\title{
Alcohol Consumption And Smoking: A Risk Factor For Psoriasis
}

\author{
L Qassim Al-Rubaiy, K Al-Rubiay
}

\section{Citation}

L Qassim Al-Rubaiy, K Al-Rubiay. Alcohol Consumption And Smoking: A Risk Factor For Psoriasis. The Internet Journal of Dermatology. 2005 Volume 4 Number 2.

DOI: $\underline{10.5580 / 1 \mathrm{~d} 5 \mathrm{~b}}$

\section{Abstract}

Background: Psoriasis is a multifactorial chronic skin disease. As in other chronic disorders various lifestyle factors have been associated with its morbidity.

Objectives: To study the association between smoking, alcohol consumption among males and psoriasis diseases.

Design: The design of study was case-control study

Setting: Cases and controls were selected from Basrah General Hospital (BGH), Sadder Teaching Hospital (STH) and private clinic of dermatology (P.C)in Basrah .Iraq

Methods: The data were collected by using questionnaire form through personal interviewing of cases and control males only to give information about the effects of smoking and alcohol on the course of the diseases. Patients with newly diagnoses of skin diseases other than psoriasis were considered as control group.

Results: A total number of patient with psoriasis was 98 patients, 47(48\%) were males and $51(52 \%)$ were females, while the controls was 242 patients, $116(48.0 \%)$ were males and 126 (52.0\%) were females. For the purpose of estimation the risk among males only, it was carried out by calculation of $\mathrm{X} 2, \mathrm{OR}$, and $95 \% \mathrm{Cl}$ of OR. The risk for psoriasis was higher in current males smokers than those patients who never smoked. The association with smoking was very significant with $(P=0.008, O R$ $=2.696,95 \% \mathrm{C} . \mathrm{I}$ of $\mathrm{OR}=1.27-5.71$ ) .Similar to smoking, there was significant association with alcohol consumption with ( $\mathrm{P}=$ $0.012, \mathrm{OR}=2.73,95 \% \mathrm{Cl}$ of $\mathrm{OR}=1.23-6.08)$.

Conclusions: Cigarette smoking and alcohol consumption are associated with psoriatic males .

\section{INTRODUCTION}

In epidemiology, any characteristic associated with a disease can be called an exposure or risk/actor .Risk can be defined as the probability of an individual developing a condition, over a specified time although this association does not necessarily have to be causal $\left[{ }_{11}\right]$.Psoriasis is a common , genetically determined chronic skin disease and by defects in the normal cycle of epidermal development that lead to epidermal hyper proliferation, altered maturation of skin cells, and vascular changes and inflammation. The condition typically manifests as areas of thickened, flaky, silvery white and reddened skin that may hurt, itch, and bleed which typically affected extensor surfaces of the body and the scalp $\left[{ }_{2}\right]$. As in other chronic disorders, various lifestyle factors either exogenous or endogenous factors have been associated with its morbidity. Epidemiological studies have been found that a large number of triggering or aggravating factor such as smoking and drinking alcohol have an influence on psoriasis and have receiving some attention in recent year $\left[{ }_{3,4,5,6,7}\right]$. The possibility that simple modifications in lifestyle may reduce both the prevalence and severity of psoriasis offers an exciting potential adjunct to treatment in the future $\left[{ }_{7}\right]$.Naldi etal have recently confirmed that smoking is associated with psoriasis with 
evidence of dose-response relationship. The risk appeared to be modified by gender. The adjusted odds ratio (OR) of smoking 15 cigarettes or more was 3.2 in women and 1.6 in men. Interestingly, the risk in pustular lesions was 9.918).In a case-control study, Poikolainen et al analyzed exposure before the onset and demonstrated a moderate increase in risk for alcohol and also alcohol has been associated with chronicity .severity of psoriasis , and treatment failure $\left[_{3}\right]$.

Palmpoplantcr pustulosis (PPP) is a form of pustular psoriasis has been very highly correlated with smoking in some studies $\left[9,_{10},,_{11},{ }_{12},{ }_{13}\right]$. And, an Italian study found the odd ratio that a person smoked was ten times higher in patients with pustular psoriasis versus the normal population $\left[{ }_{12}\right]$. Study from Sweden point towards the mechanism of this correlation suggested that certain types of cellular receptors are greatly affected by nicotine with an abnormal response to nicotine in patients with PPP which could result in inflammation. [ $\left.{ }_{11}\right]$.

\section{METHODS}

The eligibility criteria required for diagnosis of cases and controls in our study consist of combination of symptoms and signs . all cases and controls were matched on the bases of similarity with respect to age and sex . Sources of cases and controls were Basrah General Hospital (BGH), Sadder Teaching Hospital (STH) and private clinic of dermatology (P.C). The total number of cases was 98 patients, 47(48\%) were males and 51(52\%) were females, while the controls was 242 patients, $116(48.0 \%)$ were males and $126(52.0 \%)$ were females. The data were collected by using questionnaire form through personal interviewing with males only to give information about the effect of smoking and alcohol on the course of the psoriasis. The result were represented in simple tables and for the purpose of estimation of risk it was carried out by calculation of $\mathrm{X}^{2}$ ,OR, and $95 \%$ CI of OR .

\section{RESULTS}

The distribution of the cases and controls with respect to age and sex are almost compatible and no statistical differences were found. The sources of cases, controls and sex distribution was showing in [Table-1]. The commonest skin diseases of controls were bacterial infections 47(19.4\%), followed by dermatitis /eczema $30(12.4 \%)$. Significant differences was found with respect to smoking between cases and controls where the difference was very significant $\left(\mathrm{X}^{2}=6.95 \mathrm{P}=0.008, \mathrm{OR}=2.70,95 \%\right.$ C.I of OR ${ }^{==} 1.27-$ 5.71 ).With respected to alcohol consumption, Similar to smoking, the association was significant $\left(\mathrm{X}^{2}=6.32, \mathrm{P}=\right.$ $0.012, \mathrm{OR}=2.73,95 \% \mathrm{Cl}$ of $\mathrm{OR}=1.23-6.08)$ [Table -2 ].

\section{Figure 1}

Table 1: The distribution of cases and controls according to their sources and sex.

\begin{tabular}{|l|l|l|l|l|l|l|l|}
\hline \multirow{3}{*}{ Sex } & \multicolumn{9}{|l|}{ Sources* } & \multicolumn{2}{l|}{ Total } \\
\cline { 2 - 7 } & Cases & \\
\cline { 2 - 7 } & BGH & STH & PV & BGH & STH & PV & \\
\hline Males & 20 & 17 & 10 & 50 & 40 & 26 & 163 \\
\hline Females & 25 & 7 & 19 & 60 & 34 & 32 & 177 \\
\hline Total & 45 & 24 & 29 & 110 & 74 & 58 & 340 \\
\hline \\
"BGH -Basrah General Hospital \\
STH -Sadder Teaching Hospital \\
PV - Private clinic of Dermatology
\end{tabular}

\section{Figure 2}

Table 2: Distribution of cases and controls to cigarette smoking and alcohol consumption among males only .

\begin{tabular}{|c|c|c|c|c|c|c|c|c|}
\hline \multirow[t]{3}{*}{ Exposure } & \multicolumn{4}{|c|}{ Alcohol consumption } & \multicolumn{4}{|c|}{ Cigarette smoking } \\
\hline & \multicolumn{2}{|c|}{ Psoriasis } & \multicolumn{2}{|c|}{ Control } & \multicolumn{2}{|c|}{ Psoriasis } & \multicolumn{2}{|c|}{ Control } \\
\hline & No. & $\%$ & No. & $\%$ & No. & $\%$ & No. & $\%$ \\
\hline Yes & 15 & 31.9 & 17 & 14.7 & 18 & 40.0 & 23 & 19.8 \\
\hline No & 32 & 68.1 & 99 & 85.3 & 27 & 60.0 & 93 & 80.2 \\
\hline Total & 47 & 100 & 116 & 100 & $47^{*}$ & 100 & 116 & 100 \\
\hline$X / P$ & \multicolumn{4}{|c|}{$6.32 / 0.012$} & \multicolumn{4}{|c|}{$6.950 / 0.008$} \\
\hline OR $^{* *}$ & \multicolumn{4}{|c|}{2.730} & \multicolumn{4}{|l|}{2.70} \\
\hline $95 \% \mathrm{Cl}^{\ldots n}$ & \multicolumn{4}{|c|}{$1.23-6.08$} & \multicolumn{4}{|c|}{$1.27-5.71$} \\
\hline
\end{tabular}

Ex smoking very few (2) were excluded

" $\mathrm{OR}=$ odds ratio

$* * 95 \%$ Confidence intervals of odds ratio.

\section{DISCUSSION}

Tobacco smoking seriously affects internal organs, particularly the heart and lungs, but it also affects a person's appearance by altering the skin and body weight and shape. While these changes are generally not as life threatening as heart and lung disease, they can, nevertheless, increase the risk of more serious disorders and have a noticeable aging effect on the body. There are multiple risk factors for most of skin diseases and often the risk factors are correlated with each other . Case-control is one of the analytic epidemiological method to test risk factors with respect to the occurrence of specific diseases,

This study was designed to study the association between selected risk factors alcohol consumption and cigarette smoking among males with psoriasis and patients with other skin diseases .Measurement of association was done by $\mathrm{X}^{2}$ and OR and $95 \%$ of CI of OR.

The result of the study showed significant association with males psoriatic for both risk factors. About $40.0 \%$ of 
psoriasis reported history of smoking compared to $19.8 \%$ smoking controls. Alcohol consumption was reported among $31.9 \%$ of psoriatic cases compared to $14.7 \%$ of control which was consistent with many studies in recent years which suggested the correlation with alcohol, smoking and psoriasis with convincing evidence $\left[{ }_{3,4,5,6,7}\right]$.In a study in Norway, it was showed that alcohol consumption had been linked to onset of psoriasis $\left[_{3}\right]$.

Psoriasis is believed to be genetically linked but can also be triggered by several factors which have been identified as being associated either with causation of psoriasis or with triggering exacerbation or remissions and also associated with chronicity, severity and treatment failure of psoriasis including cigarette smoking and alcohol consumption $\left[2,8,,_{11}, 1_{4}\right]$. These results suggest that cigarette smoking and alcohol consumption highly associated with psoriasis.

\section{CORRESPONDENCE TO}

Kathem K Al-Rubiay. Assist. Professor . of Dermatology . Head Department of Dermatology . Basrah general hospital . College of Medicine, University of Basrah . PO .Box 289Ashar Basrah . Iraq. e-mail-kadhim1000@yahoo.com

\section{References}

1. Herd RM .Measures of diseases frequency and risk .In :William He, Strachan DP ,Eds. The challenge ofdermato epidemiology . Boca Roton ,New York :CRC Press, 1997 ;25-36

2. Peters BP; Weissman FG; Gill MA. Pathophysiology and treatment of psoriasis. Am J Health Syst Pharm. 2000 Apr 1;
57(7): 645-59.

3. Poikolainen K,Reunala T,Karvonen J,Lauhranta

J,Karkkainen P. "Alcohol intake: a risk factor for psoriasis in young and middle aged men?" Br Med J 1990 Mar 24;300(:780-3

4. Mills CM, Srivastava ED, Harvey M, et al ."Smoking habits in psoriasis: a case control study." Br J Dermatol 1992 Jul;127(1):18-21

5. Naldi L, Parazzini F, Brevi A ,et al. "Family history, smoking habits, alcohol consumption and risk of psoriasis.", Br J Dermatol 1992 Sep;127(3):212-7

6. Raychaudhuri SP; Gross, J . Psoriasis risk factors: role of lifestyle practices Cutis. 2000 Nov; 66(5): 348-52

7. Higgins,-E . Alcohol, smoking and psoriasis. Clin Exp Dermatol. 2000 Mar;

25(2): 107-10

8. Naldi L,Parazzini F, Bravi A et al. Family history ,smoking habits, alcohol consumption and risk of psoriasis .Br J Dermatol 1994 ; 130-475.

9. Akiyama T, seishima M, Watanabe H, JNakatani A, Mori S, Kitajima Y. "The relationships of onset and exacerbation ofpustulosis palmaris et plantaris to smoking and focal infections. J Dermatol 1995 Dec;22(12):930-4

10. Kubeyinje and Belagavi, "Risk factors for palmo-plantar pustulosis in a developing country . Eas Afr Med J 1997 Jan;74(1):54-5

11. Eriksson MO, Hagforsen E, Lundin IP, Michaelsson G . "Palmoplantar pustulosis: a clinical and immunohistological study." The Br J Dermatol 1998 Mar;138(3):390-8

12. Naldi L, Peli L,Parazzini F . "Association of early-stage psoriasis with smoking and male alcohol consumption: evidence from an Italian case-control study." Arch Dermatol 1999 Dec;135(12):1479-84

13. Hagforsen E, Eriksson MO, Lundin IP, Michaelsson G."Expression of nicotinic receptors in the skin of patients with palmoplantar pustulosis." The Br J Dermatol 2002 Mar;146(3): 383-91

14. Plunkett and Mark.A review of the epidemiology of psoriasis vulgaris in the community." The AustJ Dermatol 1998 Nov;39(4):225-32 . 


\section{Author Information}

Laith K. Qassim Al-Rubaiy, MBChB, MSc.

King's College, St John's, Institute of Dermatology

Kathem K. Al-Rubiay, MSc ,PhD

Assis. Professor of Dermatology, Head, Department of Dermatology, Basrah General Hospital, College of Medicine, University of Basrah 